\title{
Measurement of Power Quality on the COTEK S1500-124 Inverter's Terminals in Case of Linear Load Supplying
}

\author{
Dusan Medved*, Martin Kanalik \\ Technical University of Kosice, Department of Electric Power Engineering, Masiarska 74, 04201 Kosice, Slovak Republic \\ *Corresponding Author: Dusan.Medved@tuke.sk
}

Copyright $@ 2014$ Horizon Research Publishing All rights reserved.

\begin{abstract}
This paper describes the approach and results of power quality measurement at the outputs of DC/AC inverter COTEK S1500-124 supplying a linear load. There were used load examples as a classic light bulb of $150 \mathrm{~W}$ nominal power and an air heater with adjustable power chosen as linear load. The measurement was realized for purposes of verification of power quality indexes at the outputs of DC/AC inverter COTEK S1500-124 declared by its manufacturer.
\end{abstract}

Keywords Power Quality, Power Quality Measurement, Harmonics, DC/AC Inverter

\section{Introduction}

Currently, there is increased emphasis to use the renewable energy sources in our society places. Among the most common utilizing of energy from the sun belong the photovoltaic conversion cells. Electrical energy from the photovoltaic panels in the form of DC voltage and current is necessary for the purpose of further distribution or another use by converting to alternating voltage with variable $\mathrm{DC} / \mathrm{AC}$ inverters. Because the voltage at the inverter output is generated by semiconductor devices, it is necessary to deal with the issue of the quality of source voltage. Our Department of Electrical Power Engineering, at Faculty of Electrical Engineering and Informatics, Technical University of Kosice was installed electrical network consisting of a source of electrical energy (photovoltaic panels and wind turbine), regulators, batteries and inverters for research purposes and the impact of potential uses of photovoltaic panels and wind turbine on the quality of electricity supply. The realization of island operation of this network helped to carry out the measurement of quality indicators of electricity output inverter COTEK S1500-124 that powered the linear load and the results of this measurement are described in this article. The measurement was limited by battery capacity, that powered the inverter and because the measurement was carried out for linear power load it is possible consider the similar results also for the long term measurement (hence for one week measurement).

\section{Power Quality Indexes}

This chapter briefly characterizes the individual quality indicators of voltage that were measured and evaluated. On the score of that it was a one-phase measurement, and there was not measured asymmetry coefficient. Because it was a relatively short measurement, the flicker was not measured. During the measurement there were evaluated: frequency, RMS voltage and harmonic distortion.

\subsection{Power Frequency Variations}

Power frequency variations are defined as the deviation of the power system fundamental frequency from its specified nominal value (e.g., 50 or $60 \mathrm{~Hz}$ ). In the EN 50160 standard it is mentioned that under normal operating conditions the mean value of the fundamental frequency measured over $10 \mathrm{~s}$ shall be within the range of $50 \mathrm{~Hz} \pm$ $2 \%$ (i.e. between $49 \mathrm{~Hz}$ and $51 \mathrm{~Hz}$ ) during $95 \%$ of a week and within the range of $50 \mathrm{~Hz} \pm 15 \%$ (i.e. between $42.5 \mathrm{~Hz}$ and $57.5 \mathrm{~Hz}$ ) during $100 \%$ of the time in the case of systems with no synchronous connection to an interconnected system (e.g. supply systems on certain islands).

\subsection{Supply Voltage Variations}

Harmonic distortion is generally caused especially by non-linear devices (whose demanded current is not proportional to the supply voltage), that are connected to the power system. Using the Fourier analysis it is possible to factorize the deformed distribution wave to sum of pure sine waves whose frequencies are the integer multiples of the fundamental frequency of the deformed wave. These integer multiples are called harmonics of the fundamental frequency [3].

The most used quantity determining the presence of harmonics in electrical networks is the THD factor (Total 
Harmonic Distortion). THD coefficient for the measured variable (voltage, current) can be determined as follows [3]:

$$
T H D=\frac{\sqrt{\sum_{h>1}^{h} M_{h}^{2}}}{M_{1}}
$$

where: $M_{h}$ - effective value of the $h$-th harmonic of the measured quantity, $h$ - harmonic order.

\section{Measurement Description}

Measuring of the electricity quality on the output of inverter COTEK S1500-124 (Figure 1) was performed using the power quality analyzer Class A - ENA330 (Figure 2). The simplified diagram of batteries connection, inverter, load and power quality analyzer is shown in Figure 3. Power quality analyzer was set to measure data of the sampling rate of 9600 samples/second and with data collection of the interval of $200 \mathrm{~ms}$. The total length of the measurement was about 10 minutes. During this time there were sequentially measured four operating regimes:

- inverter COTEK S1500-124 without load

- inverter COTEK S1500-124 loaded by light bulb with a rated output of $150 \mathrm{~W}$ (approx. 4 minutes)

- inverter COTEK S1500-124 loaded by water heater with a rated power output $1160 \mathrm{~W}$ (about 4 minutes)

- inverter COTEK S1500-124 overloaded by air heater with a rated power output $1850 \mathrm{~W}(30 \mathrm{~s})$.

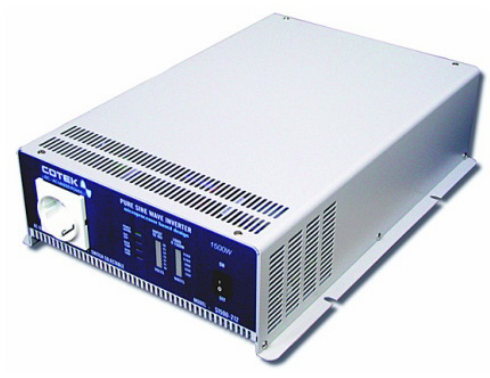

Figure 1. COTEK S1500 - Pure Sine Wave Inverter

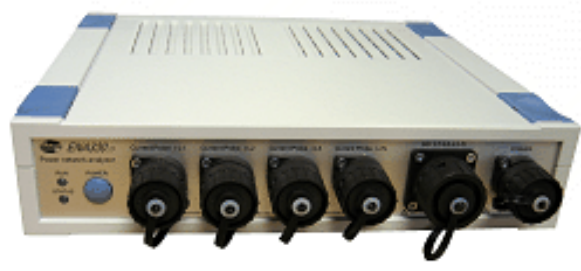

Figure 2. Power quality analyzer - ENA330

\section{Evaluation of Measured Data}

As it was mentioned in the previous chapter, during the measuring of the quality indicators of electricity on the output of inverter COTEK S1500-124 there was implemented the gradual change of the load. In Figure 4 there is shown the characteristics of the total active power drawn from the inverter for the entire duration of measurement with the indicating of the four specific load areas. In the fourth regime, where the inverter was overloaded (the rated power of the inverter was $1500 \mathrm{~W}$ ), the operation time was influenced by the time of overload protection inverter, which switch off the inverter up to 30 seconds from the overload occurrence. Characteristics of RMS voltage value during the entire measurement period are shown in Figure 5. As one can see, the RMS voltage value at the inverter output is in the range of nominal value, even during the sudden load changes. The RMS voltage value during the entire measurement period (even during overload) did not fall down below the $98.5 \%$ of the nominal value $(230 \mathrm{~V})$.

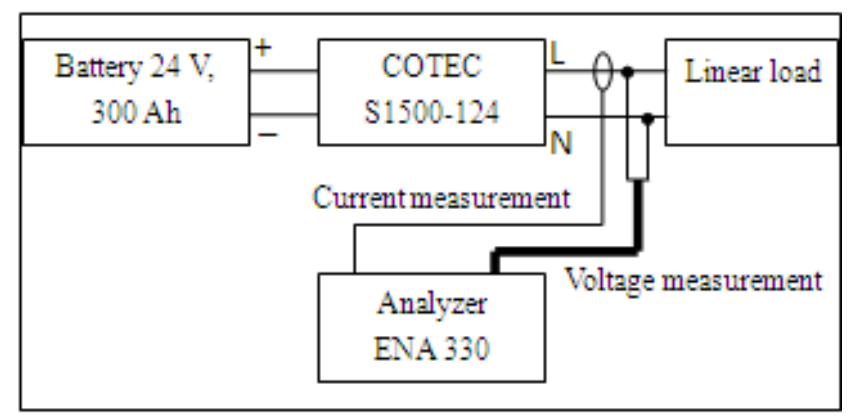

Figure 3. Simplified diagram of connection of batteries, inverter, load and power quality analyzer

The Figure 6 shows the characteristics of the frequency during the entire measurement period. In this case, it should be noted that the measurement was carried out in the island operation, battery-inverter-linear load with a relatively large changes in load. As one can see from the characteristics of the RMS voltage value and frequency, neither the sudden load change from $0 \%$ to $80 \%$ of the nominal output voltage did not cause a significant decrease or change of the frequency. From this perspective, it is possible the inverter COTEK S1500-124 (powered by 300 Ah battery) considered as the relatively hard source.

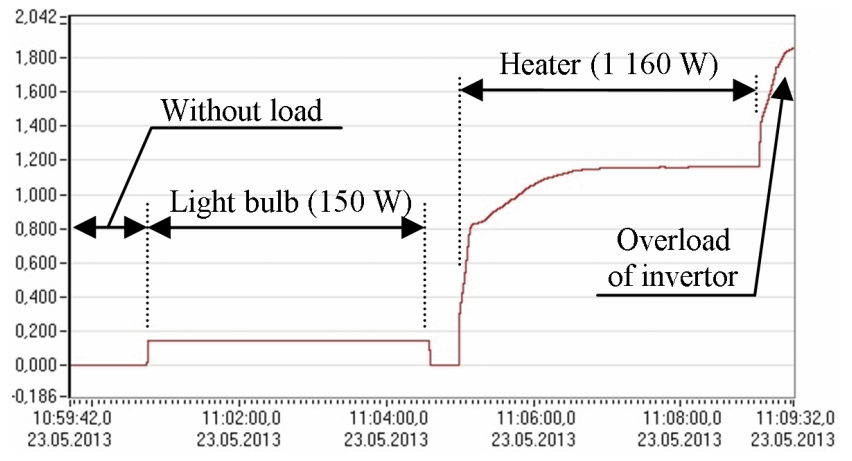

Figure 4. The characteristic of the total active power during the measurement

Figure 7 shows the characteristics of the total harmonic voltage distortion $\left(\mathrm{THD}_{\mathrm{U}}\right)$ during the overall measurement 
duration. Because from the inverter COTEK S1500-124 supplied during the measurement only the linear load, the measured values can be considered as the values of the coefficient of total harmonic distortion of voltage that characterize the deformation of voltage generated by inverter COTEK S1500-124 The manufacturer declares the value of the coefficient $\mathrm{THD}_{\mathrm{U}}<3 \%$. In the case of linear load feeding there was measured the coefficient $\mathrm{THD}_{\mathrm{U}}$ less than $1 \%$, regardless of the size of the load.

U AVG [V]

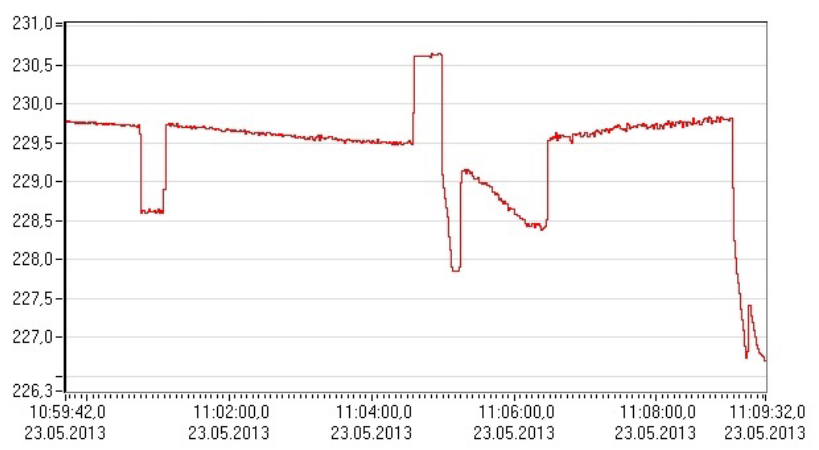

Figure 5. The characteristics of the total RMS voltage during the measurement

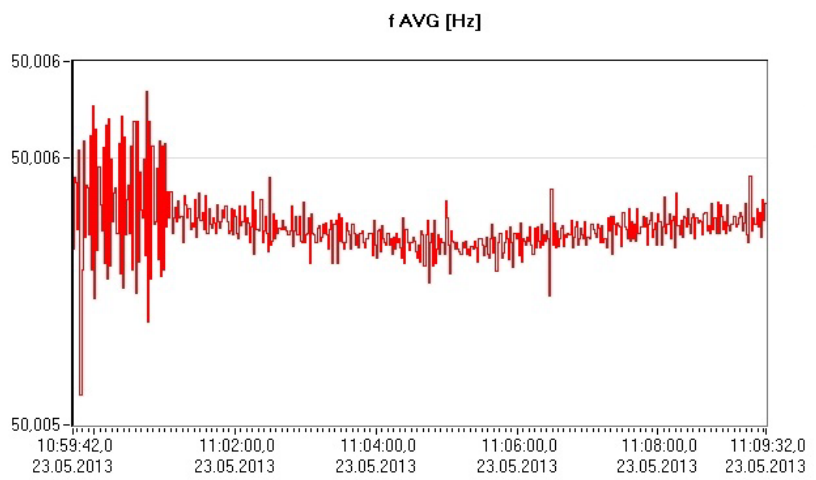

Figure 6. The characteristics of the frequency during the measurement

THD U [\%]

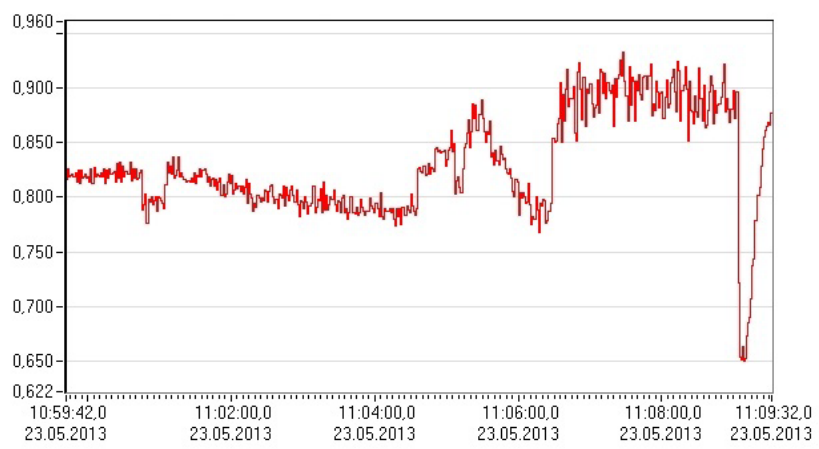

Figure 7. The characteristics of the total harmonic voltage distortion $\left(\mathrm{THD}_{\mathrm{U}}\right)$ during the measurement

Figures 8 to 10 show the harmonic spectrum of voltage in volts for the state inverter with no load; the status of the inverter loaded by a light bulb with a rated output of $150 \mathrm{~W}$ and the inverter loaded by the heater with power of $1160 \mathrm{~W}$ These harmonic spectra are immediate harmonics in voltage during the measurement of individual states. One can see from the particular figures the decreasing size of the effective values by the order of the individual harmonics, while in the case of no-load condition and load of $150 \mathrm{~W}$ (light bulb) the harmonic voltages higher than 15 orders of magnitude are practically non-existent. Harmonic spectrum in both cases is very similar (as well as the size of $\mathrm{THD}_{\mathrm{U}}$ ). The difference can be seen particularly by the harmonic order of 6 and 10 in the case of loading by the light bulb, while in the case of no-load condition; these harmonic voltages are not present.

U Harmonic $3.0[\mathrm{~V}]$

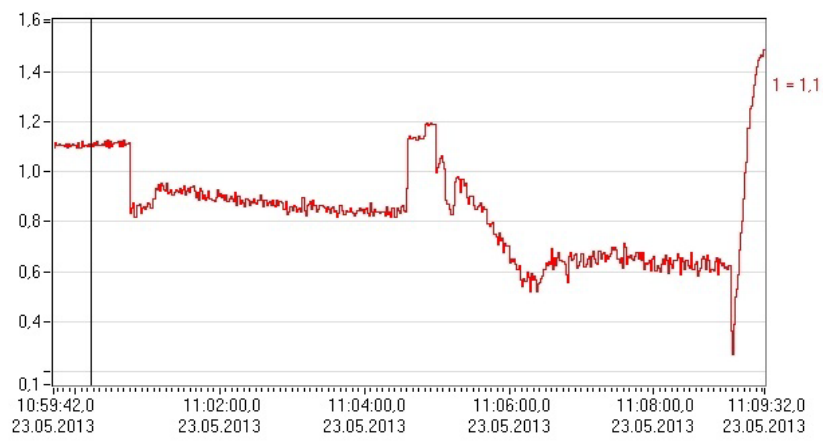

Figure 8. The characteristics of the $3^{\text {rd }}$ harmonic of voltage during the measurement

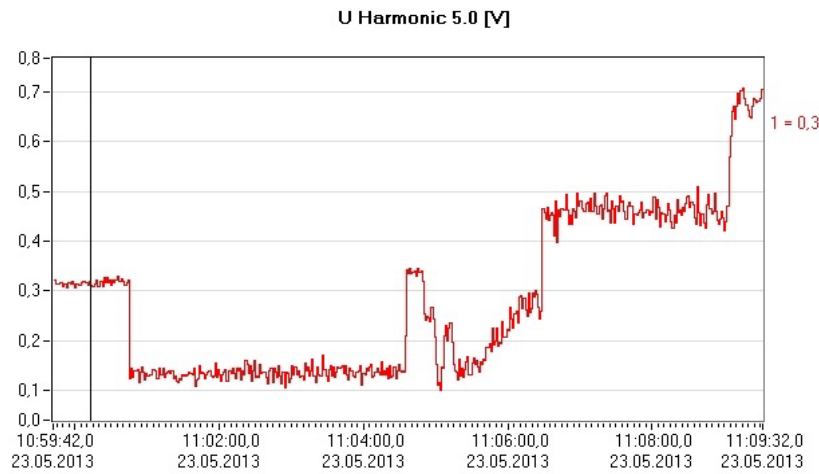

Figure 9. The characteristics of the $5^{\text {th }}$ harmonic of voltage during the measurement

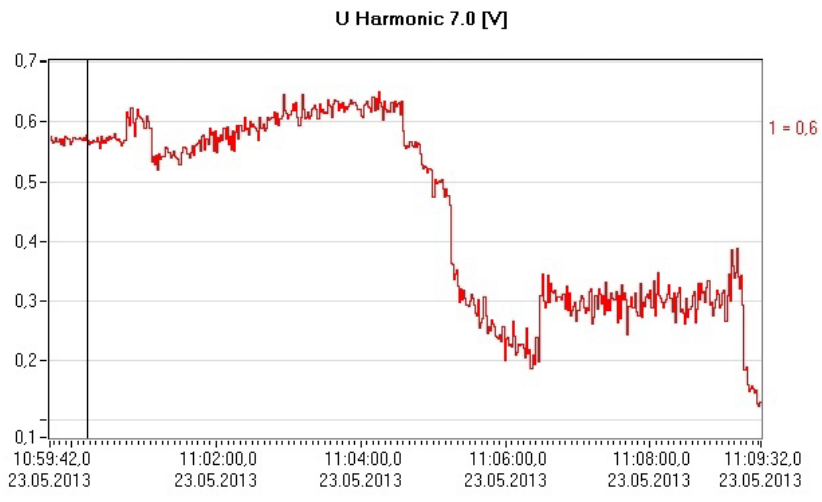

Figure 10. The characteristics of the $7^{\text {th }}$ harmonic of voltage during the measurement 
I Harmonic 1.0 [A]

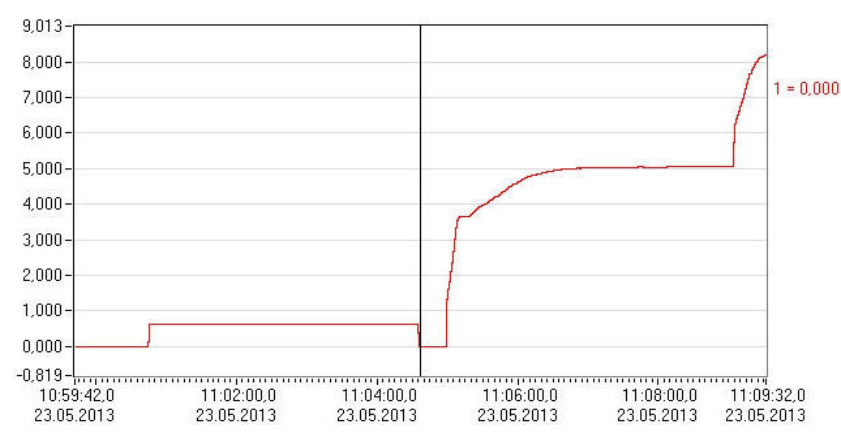

Figure 11. The characteristics of the $1^{\text {rd }}$ basic harmonic of current during the measurement

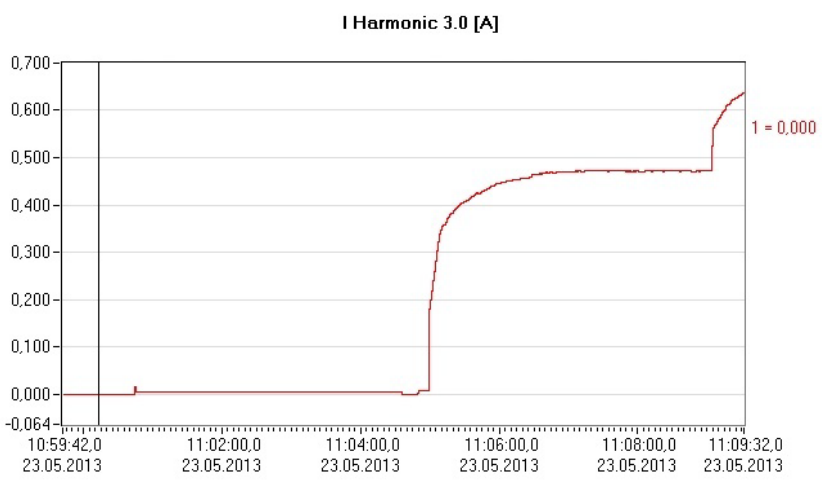

Figure 12. The characteristics of the $3^{\text {rd }}$ harmonic of current during the measurement

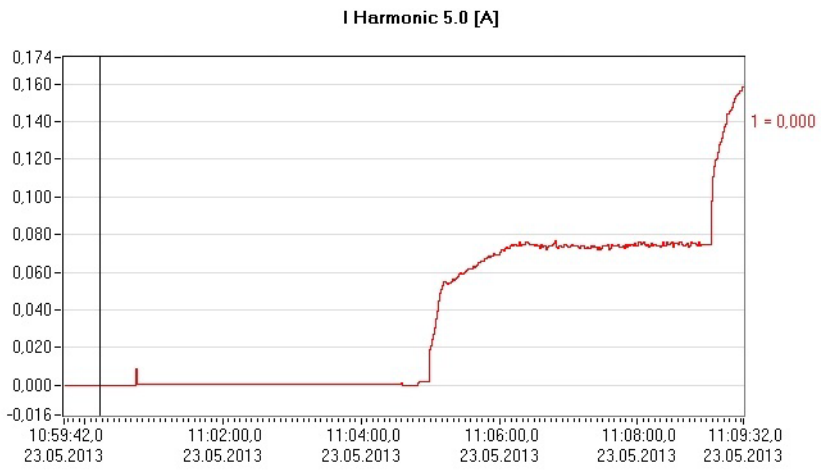

Figure 13. The characteristics of the $5^{\text {rd }}$ harmonic of current during the measurement

I Harmonic $7.0[\mathrm{~A}]$

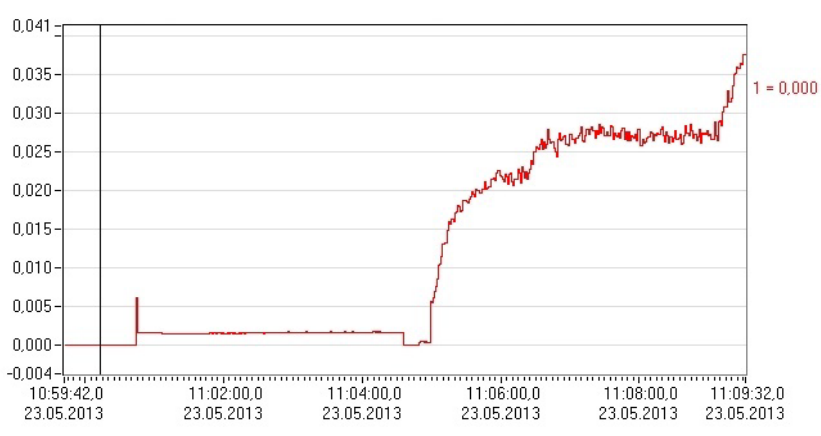

Figure 14. The characteristics of the $7^{\text {rd }}$ harmonic of current during the measurement

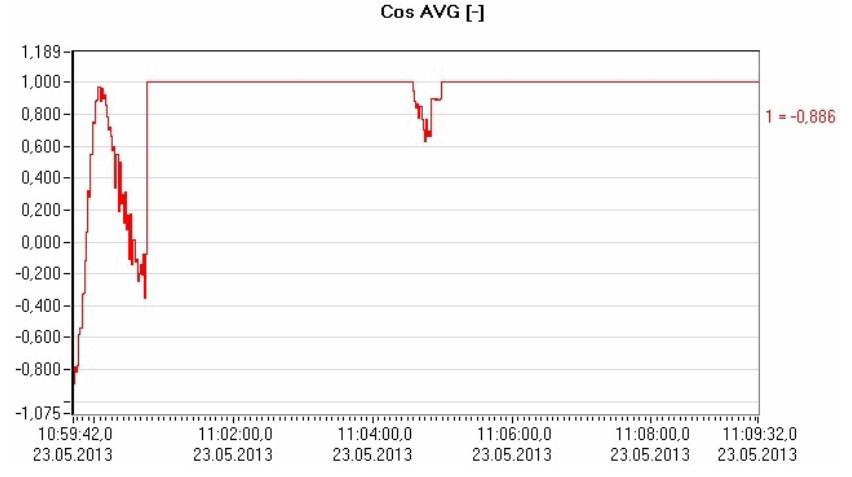

Figure 15. The characteristics of the displacement power factor $(\cos \varphi)$ during the measurement

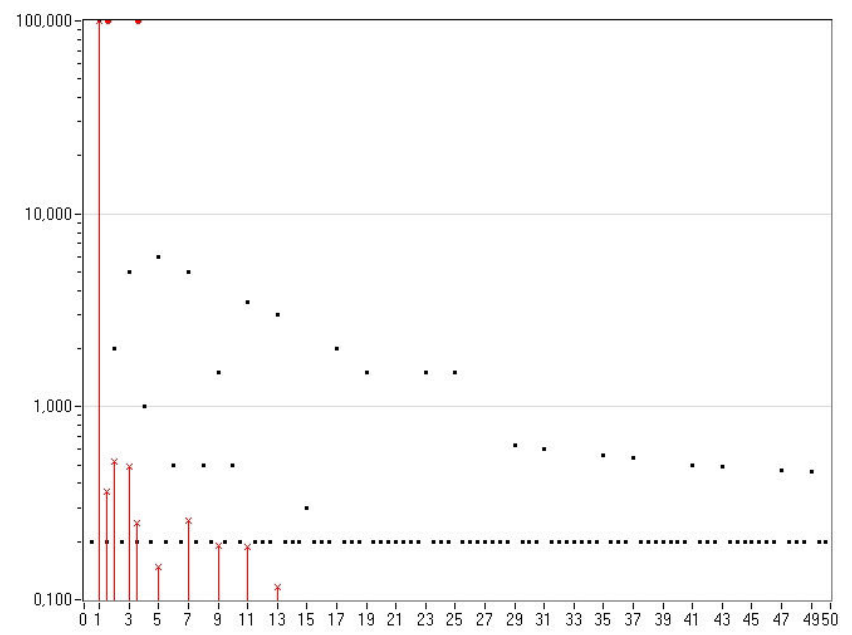

Figure 16. The harmonic spectrum of the output voltage of the inverter during the no-load operation

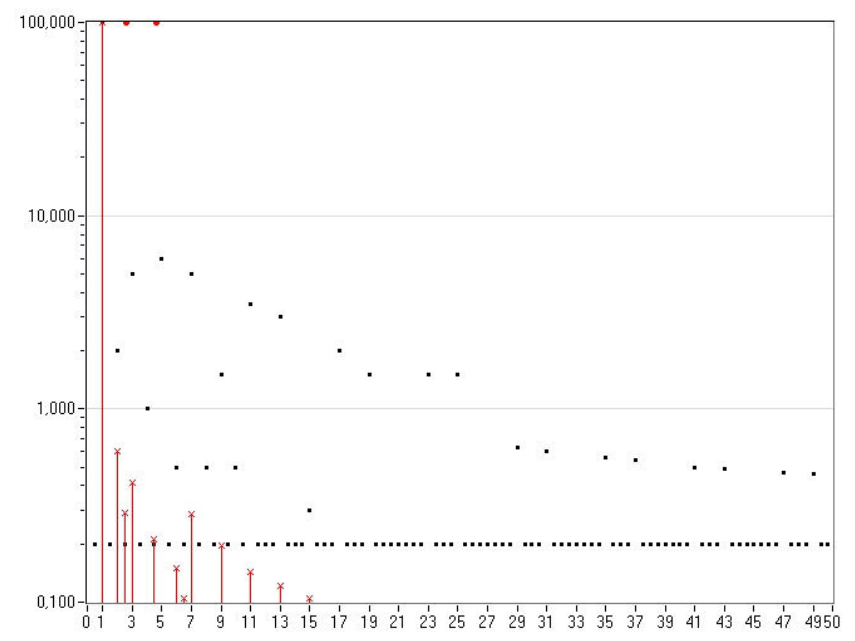

Figure 17. The harmonic spectrum of the output voltage of the inverter powering the light bulb by nominal power of $150 \mathrm{~W}$

On the other hand, after the connecting of the $150 \mathrm{~W}$ light bulb to the inverter output there was indicated the decreased levels of $5^{\text {th }}$ harmonic of the voltage. In the case of the harmonic spectrum of the output voltage of the inverter that powered the heater of nominal power of $1160 \mathrm{~W}$ (Figure 10) one can see the presence of the each harmonic to the order of 
16, although their effective values are relatively low. Fig. 16 to Fig. 18 represents voltage harmonics with limit labeling according to STN 61000-2-4, class 2, what is indicated also in standard EN 50160. During the measurement of harmonic in no load operation, there were observed also interharmonics, respectively 2nd harmonics, but the manufacturer did not declare it.

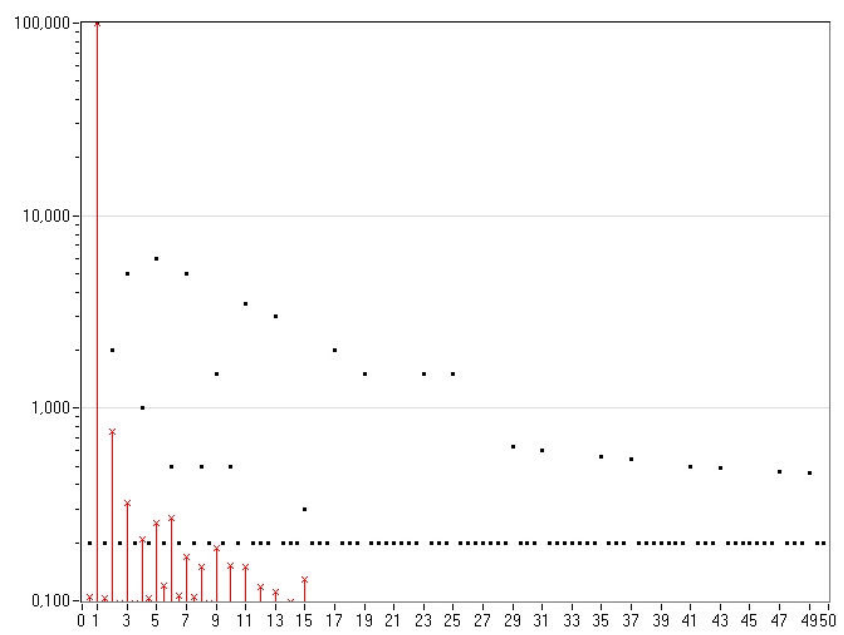

Figure 18. The harmonic spectrum of the output voltage of the inverter powering the air heater by nominal power of $1160 \mathrm{~W}$

\section{Conclusion}

The measuring of the frequency level, RMS voltage and the total harmonic distortion on the output of inverter COTEK S1500-124 in no-load state, supplied the linear load at nominal power of $150 \mathrm{~W}$, and linear load with power of $1160 \mathrm{~W}$ and a linear load with the input of more than $1500 \mathrm{~W}$ demonstrated the compliance with the limits specified by the manufacturer of this inverter. In no case of the measured states there was not exceeded the value of $\mathrm{THD}_{\mathrm{U}} 1 \%$. According this measurement with the registration of measured data every $200 \mathrm{~ms}$, it can be stated on the basis of the measured results that in the case of feeding of linear load the power quality indicators were within the limits prescribed by standards [1], respectively [2] with a sufficient reserve: RMS, $\mathrm{THD}_{\mathrm{U}}$, as well as the frequency of the inverter terminals COTEK S1500-124. The authors will verify the compliance within the limits given in the case of non-linear loads connected to the inverter terminals within the future work.

\section{Acknowledgements}

This work was supported by the Scientific Grant Agency of the Ministry of Education of Slovak Republic and the Slovak Academy of Sciences by the projects VEGA No. 1/0388/13.

\section{REFERENCES}

[1] EN 61000-2-2, "Electromagnetic compatibility (EMC) - Part 2-2: Environment - Compatibility levels for low-frequency conducted disturbances and signalling in public low-voltage power supply systems", March 2002

[2] EN 50160 "Voltage characteristics of electricity supplied by public distribution systems", February 2011

[3] Dugan, R., C., McGranaghan, M., F., Santoso, S., Beaty, H., W.: "Electrical Power Systems quality", second edition, 2003, McGraw-Hill, ISBN 0-07-138622-X

[4] Medved, D.: "Utilising of EMTP ATP for Modelling of Decentralized Power Sources Connection". In: Transactions on Electrical Engineering: International scientific journal for electrical engineering, Vol. 2, No. 1 (2013), p. 26-29, ISSN 1805-3386.

[5] Medved, D.: "Modeling of Power Systems Using of Matlab/SimPowerSystem". In: Elektroenergetika. Vol. 5, No. 2 (2012), - ISSN 1337-6756. 